\title{
Study with Family Members of Patients in the Intensive Care Unit: An Intervention of Medical Undergraduates
}

\author{
Danielle Abdel Massih Pio, Debora Aiesha Leite Cantelli, Ivan de Melo Araújo, \\ Karen Mayumi Matsuno, Karin Kojima, Rubens Yoshinori Kai \\ Faculdade de Medicina de Marília, Marília, Brazil \\ Email: karinkojima@hotmail.com
}

How to cite this paper: Pio, D. A. M., Cantelli, D. A. L., de Melo Araújo, I., Matsuno, K. M., Kojima, K., \& Kai, R. Y. (2017). Study with Family Members of Patients in the Intensive Care Unit: An Intervention of Medical Undergraduates. Creative Education, 8, 1742-1760. https://doi.org/10.4236/ce.2017.811119

Received: June 23, 2017

Accepted: September 2, 2017

Published: September 5, 2017

Copyright $\odot 2017$ by authors and Scientific Research Publishing Inc. This work is licensed under the Creative Commons Attribution International License (CC BY 4.0).

http://creativecommons.org/licenses/by/4.0/

\begin{abstract}
Attention to the family members of patients hospitalized in Intensive Care Units (ICUs) is one of the most important items of the global patient care. The present study involves the health needs of the relatives of patients hospitalized in ICUs of a school hospital of a Higher Education Institution (HEI) located in a Brazilian State (São Paulo). This HEI, with a differentiated curriculum in the country, aims at the practical/theoretical integration and teaching/service articulation. In this context, a research-action study was carried out by professors and students of this HEI, raising the main demands of relatives of specific age groups of patients admitted to the ICU. This step subsidized the formulation and application of interventions in these scenarios, in order to address the needs presented. Based on a qualitative analysis of interviews conducted, we discussed three thematic categories: the experience of having a relative in the ICU; the reference professional and the family perspective on the reception and care of the team; the quality of family-patient contact in the ICU. We emphasize the importance of dialoguing with the family members about the experiences they are having, as well as orienting them about the dynamics of the ICU's environment, the patient's condition, the procedures being performed and the purposes of the equipments used. The attention to the family of a patient hospitalized in an ICU should not be forgotten, being recognized as an important care of the multiprofessional team.
\end{abstract}

\section{Keywords}

Intensive Care Unit, Professional-Family Relations, Doctor-Patient Relationship, Medical Students, Hospital Humanization 


\section{Introduction}

Intensive Care Units (ICUs) are intended for patients with severe and potentially recoverable conditions, where the hospitalization of a person usually affects and weakens the family of the patient in question (Brasil, 2004; Santos \& Caregnato, 2013). It is known that the family can contribute a lot to the patient's recovery, but for this to happen, it needs to be guided about the routines of the ICU and about what is happening with the family member, needing to feel welcomed, respected and, also, cared for (Freitas, Kimura, \& Ferreira, 2007; Santos \& Caregnato, 2013; Silveira, Lunardi, Lunardi Filho, \& Oliveira, 2005).

Although there are several peculiarities of each group, both the pediatric and the geriatric hospitalization scenario generate to the family certain behaviors and feelings, such as: doubts, helplessness, mental disorganization, immobilization in the face of unexpected decisions and other reactions, such as depression and/or illnesses generated by stress, concern and anxiety. In fact it is common to find in the literature questionnaires and indicators that show a high level of anxiety and stress among family members of hospitalized patients (Martins et al., 2008).

Thus, attention to family members is one of the most important parts of the global care of ICU patients, so that they can experience this moment more evenly (Bousso \& Angelo, 2001; Poles \& Bousso, 2006; Soares, 2007). This commitment falls on the health team, whose actions must go beyond the technical and pharmacological interventions focused on the patient, including assessing the needs of the family members (Martins et al., 2008).

In this perspective, health needs are not restricted to biological demands, nor can they be considered as individual and isolated (Moraes, Bertolozzi, \& Hino, 2011).

Under the Collective Health approach, health needs are also social needs, which are heterogeneous and originate from the reproduction of life in society. Listening to the needs of the users allows health professionals to increase the capacity of attendance and to potentiate interventions directed to the problems brought by the population, which translates into greater resolubility of the care provided (Moraes, Bertolozzi, \& Hino, 2011). Humanized practices aim to meet the physical, psychic and spiritual demands of the patient, the family and the team (Oliveira, Oliveira, Lucchese, Alvarenga, \& Brasil, 2013).

Nowadays, it is a challenge for these humanized attitudes to be transmitted to professional practice during medical graduation. According to the Brazilian Ministry of Health, to improve the way to care, treat and follow health, it is necessary to change the ways of teaching and learning, to review educational practices and their reflexes in actions and services (Baldoino \& Veras, 2016). Considering that, over the last few years, there have been changes in the curriculum of medical courses. The National Curricular Guidelines ("Diretrizes Curriculares Nacionais"/DCN) was had as a guiding for the organization, development and evaluation of the Medical Course within the country's higher education systems (Brasil, 2014). 
The Art 3 of the DCN of 2014 presents that "the medical graduate will have general, humanistic, critical, reflexive and ethical training, with capacity to act at the different levels of health care, with actions to promote, prevent, recover and rehabilitate health at the individual and collective level, with social responsibility and commitment to the defense of citizenship, human dignity, the integral health of the human being and having as transversality in its practice, always, the social determination of the health and disease process" (Brasil, 2014).

In this context of curricular transformation, one HEI, located in a Brazilian State (São Paulo), develops a curriculum integrated and organized by professional competence. It uses as a pedagogical strategy the principles of active learning methodologies. The students seek to continue the development of skills in the areas of individual care, collective care and management of health services, as well as the development of scientific initiation. For this, it is based on the logic of health surveillance, with emphasis on primary care, already started in the first year of the course. In order to achieve the performances proposed for the school grade, certain actions are necessary, in which cognitive, affective and psychomotor attributes are articulated in different settings of the health care network. The responsible and committed insertion of students and teachers in the real scenarios starting from the first year of the course aims at the practical/theoretical integration, and the teaching/service articulation has been the foundation around which a new way of being, making and knowing is created (Marin et al., 2014).

With this view, this study starts from the context of ICUs with specific patient age groups. This study aims to understand the needs of family members, considering the singularities of their experiences and their reception demands. It focuses on the approach to the family members of geriatric and pediatric patients, in order to teach greater care to medical graduates. In view of the importance of this subject, embracing the humanization of care, this article seeks to present the research, analysis and intervention performed in the service and in the practical and teaching scenarios.

\section{Methodology}

Intervention study developed in the research-action modality, carried out in two phases.

The research had as subjects of study the family members of pediatric and geriatric patients hospitalized in ICUs (neonatal, pediatric, adult) of school hospitals of a HEI of medicine, located in a city of the state of São Paulo/Brazil. Researchers are undergraduate and teachers of this institution, directly involved, in their daily activities, in the scenario where the research was carried out.

The research project was evaluated and approved by the Research Ethics Committee (REC) of the HEI under number 034351/2015. The project was awarded by a scholarship from a Center of Ethics and Bioethics of the regional medical council of the state where the HEI is located. This center has as one of 
its objectives the implementation of projects and activities in the area of medical ethics and bioethics through partnerships and agreements with national and international Universities, Professional Councils, Societies of Specialties, Foundations, Entities and Governmental and Non-governmental Organizations.

The research involved a total of 30 individuals: 15 family members of pediatric patients admitted to Pediatric ICU and Neonatal ICU, and 15 family members of geriatric patients admitted to the Adult ICU. As a criteria for inclusion in the research, the subjects should have had their relatives hospitalized in the ICU for a minimum period of 3 days, and in the adult ICU, the age of the patient should have been greater than or equal to 60 , configuring an elderly patient. In the pediatric ICU there was no selection that took into account the age of the patient, since all of them were included in the category of pediatric patients. The 30 subject were randomly chosen by the researchers in the ICU waiting room environment. As exclusion criteria, relatives who were less than 18 years old and those who refused to participate in the survey were not selected.

Sample space was obtained in a non-randomized manner, using a convenience sample. The number of individuals $(\mathrm{n}=30)$ was defined in an intentional way, based on other studies with qualitative analysis, in which conclusive results were obtained with smaller sample spaces.

The research instruments were applied to the study subjects prior to their visit to the patient in the ICU, upon obtaining the signature of the Informed Consent Form (ICF) (Appendix III).

The first phase, a cross-sectional and qualitative observational analysis, uses the Lipp Adult Stress Symptom Inventory (ISSL) (Appendix II) to evaluate the stress level of the subjects, and a semistructured questionnaire (Appendix I) created by the researcher group with the aim of tracing the profile of the subjects interviewed and analyzing some of their health needs.

The analysis was quantitative and qualitative, with characterization of response frequencies and percentage, followed by a thematic analysis, using the three steps indicated by Minayo (ordering, data classification and final analysis) (Minayo, 2012).

The qualitative analysis initially divided the subjects interviewed into only two groups: the interviews done in the adult ICU and the pediatric ICU. In this analysis, gender, age, family relationship and other informations obtained in the semi-structured questionnaire were not taken into account.

The research was based on the purposes of a research-action, which uses established research techniques to investigate possible changes to be made in order to improve a practice environment in which researchers are involved. In our case, the first phase of the study, mentioned above, brought data that allowed the research group to define some support needs of the studied scenario, subsidizing the formulation of intervention plans, with the purpose of improving some fragilities (Engel, 2000).

Following the steps of a research-action, the research group should make use 
of new instruments to evaluate the effectiveness of the intervention plans implemented (Tripp, 2005). However, the effects of interventions can take months to alter new research results (Aymar, Lima, Santos, Moreno, \& Coutinho, 2014). Therefore, the research group did not have the time to monitor their actions and to evaluate the effectiveness of the interventions performed, being possible to detail in a further study.

\section{Results}

\subsection{Quantitative Analysis}

In the study, there was a predominance of women among the interviewees, corresponding to a percentage of $66.7 \%$ in the group of geriatric patients' family and $73.3 \%$ in the group of pediatric patients' family. In relation to the age range of the relatives of patients admitted to the ICU, it prevailed the age range of 18 to 28 years in pediatrics' group and age range of 40 to 50 years in geriatric's group. Regarding education degree, from those interviewed in the pediatric ICU, it has prevailed those who affirmed completed elementary school (40\%). In this group, no one completed higher education degree. Among the geriatric patients' relatives interviewed, it has predominated the complete Middle School degree (46.7\%). Among the same group, only $6.7 \%$ of the interviewed had completed university education and no one declared himself/herself illiterate. When questioned about religion, $80 \%$ of geriatric patients' relatives claimed to be religious practitioner (predominantly evangelical, 53.3\%). Among the pediatric patients' relatives, $60 \%$ stated that they were practitioners, and the Catholic religion predominated (53.3\%), but $40 \%$ said they were not religious practitioners. The majority of respondents in our study maintained a frequency of 4 times or more visits to the boarding school. Among the family members of the geriatric patients, 53.3\% stated that another family member had previously been admitted to the ICU, which falls to $40 \%$ among the pediatric patients. In both groups, more than $90 \%$ of the interviewees had never had an ICU stay. In the group of geriatric patients, $80 \%$ of the family members interviewed stated that they were not living with the patient. For the pediatric patient group, the index corresponded to $20 \%$. Regarding the results obtained from the ISSL questionnaire, in the adult ICU we did not obtain significant scores. In contrast, in the pediatric ICU, we found high stress scores, covering more than seven items of the warning signs for stress.

\subsection{Qualitative Analysis: Thematic Categories}

Three categories were obtained with the research: 1) the experience of having a relative in the ICU; 2) the reference professional and the family perspective on the reception and care of the team; 3 ) the quality of family-patient contact in the ICU. All categories contain illustrations, phrases from family members of pediatric patients (PPF) and relatives of geriatric patients (GPF).

Theme 1: The experience of having a relative in the ICU 
Both of the families from pediatric's and adult's patients hospitalized in the ICU designate the experience in an intensely bad way, bringing feelings such as insecurity, sadness and impotence. Both groups wishes the family member to be discharged as soon as possible.

What appears most strikingly in the Adult ICU scenario is the religiosity. In addition to placing expectations in the team, the family places in the figure of God the hope for improvement and healing.

In the pediatric ICU, the experience is qualified in a negative way with intensity.

"Bad. Oh I want my daughter to leave soon, it is a very bad feeling to see her here" (PPF 5);

"It is very bad. It's an experience I do not wish for anyone. It's a bad feeling, I'm really scared too. (...) I just want to get out of all this" (PPF 8)

When it comes to the hospitalization of an elderly patient, although the relatives show the same feelings of anxiety and sadness, the anguish with the hospitalization is transmitted in different ways: they are less distressed during the interviews, as they attribute support and comfort to religiosity.

"Our Lady, very difficult. Well, I feel anguish, I feel powerless to not be able to do anything, (...). I feel completely lost, it's very difficult ... but I surrendered to God's hand, because all that can be done is being done...." (GPF 8)

Thus, both groups of family members pointed out negative aspects in the hospitalization of a relative in the ICU. Family members expressed feelings such as: sadness, anxiety, fear and insecurity. In the case of the pediatric ICU, the literature indicates that the relatives-mostly represented by the parents-expect a newborn or a healthy child, not susceptible to diseases. So, the child's ICU hospitalization is felt as a very big shock, influencing the entire family dynamics (Goldenstein, 2006; Molina, Varela, Castilho, Bercini, \& Marcon, 2007).

Theme 2: The professional of reference and the familiar perspective on reception and care of the team.

The relatives of patients hospitalized in the adult ICU reported satisfaction with the treatment received from the team, both for the patient and the family. They also expressed satisfaction with the professionals' reception (who exchange information with family members according to their needs) and satisfaction with the environment, hygiene and organization. They recognize that the team works within its possibilities of human, physical and material resources.

"Wow, they're really good. They treated me very well. They treat my uncle well, too. Thank God. They treat us well and also the patient. "(GPF 1).

"Very good, they are taking good care of him. They are doing what is possible, because God is the one who solves everything."(GPF 11).

"Wow, the staff is great. Exceptional team service. Their work is very good. Wow, very good. Hygiene, attentiveness, wow, very good, they deserve 
congratulations." (GPF 8)

"In my opinion I found it great, because they do what they can, right? If something is not done, it is because of the working condition or because it has no material, because it lacks, right? Which I know is lacking. So because of that, sometimes it falls short, but for lack of having the material, right?" (GPF 14)

The reports of the relatives of hospitalized children, however, were divergent. Some relatives pointed out the good quality environment with great professionals. We can note the difficulty, however, in naming professionals and even identifying their professions:

"I know the face, I can not remember the names. But there are always those that we will talk more. But we are able to can talk to them". (PPF 12)

"Doctors always talk to me. At first it was more the nurse. They treat us well, they talk, they explain if we ask something, everything is right”. (PPF 2)

In the pediatric ICU, attention is drawn to the difficulty of the family members getting closer to the professionals, with difficulties to establish a greater bond. In terms of information and quality, there are reports of attention and availability of the team, with clarification of doubts, but there is also a balanced proportion of reports of low availability and little affective contact between staff and families of children hospitalized.

"I only know by sight, they are not the type that want to talk much." (PPF 15)

"No, there's even a doctor there who will not tell us if the baby is okay or not. It's just like: "Oh mom, everything is great". We do not know if the child is well or not. The nurses can not explain anything.” (PPF 4)

Therefore the report presents weaknesses in the communication of the medical professional with relatives, with demands not fully answered by the team. Other complaints related to the pediatric ICU refer to the few hours of visits (only 1 hour per day, 30 minutes after lunch and 30 minutes at night).

The lack of availability of professionals is not a significant complaint in the adult ICU. There are reports that the greatest contact is with the medical professional, seen as a reference professional. The nursing figure also deserves attention for the care given to the family members. In general, the quality of the information received is seen by the family as satisfactory in the Adult ICU.

"Only the doctor will come and talk to us. And when we need the nurse, he will meet us there at the time". (GPF 4)

Theme 3: Quality of family-patient contact in the ICU:

The relatives of patients hospitalized in the adult ICU bring possibilities of contact and exchange with the patient:

"Even though he's sedated, we talk to him. So I think it's important to give 
force to him, to say that everyone is praying for him and that God is in front of everything, passing this spiritual aspect and saying that he is loved".

(GPF 15)

In the pediatric ICU there seems to be greater inhibition of the relatives in relation to the approach, giving little importance to their presence. They bring the feeling of impotence in a remarkable way.

"I stay there all the time, I give my hand to my daughter. We do not have much to do right?! I just want her to be okay soon." (PPF 5)

"You can not do much, right? We only visit". (PPF 6)

Second stage of the research: intervention plan.

The intervention plans created were group specific and took into account the analysis of the data obtained in the first stage of the research.

We pointed out the need to show the data collected to the ICU staff, the humanization group of the hospitals and the technical director of the hospitals in which we operate.

With the contributions offered by the Humanization Group and the ICU teams of the HEI, explanatory manuals and folders were elaborated with the following content: identification of ICU professionals, ICU routine and hours; how the visits work; the meaning of an ICU stay. For each scenario (Adult ICU and Pediatric ICU) the content of this material had its specificities, focusing on the main needs encountered.

In addition to this material, the team of the Adult ICU proposed to offer a space of 30 minutes before the routine of visit, in which the family would be welcomed and oriented by the team. The folders and/or manuals would be delivered and explained by a member of the ICU team. These strategies would aim to create a greater bond with the family, meeting the needs of both the team and the families, making communication more effective.

Considering the teaching-service integration, the proposals were directed towards the improvement of health care in the teaching-learning scenarios. Teachers present in the assistance, by supervising the students in the practice scenarios, were involved in the discussions along with the multiprofessional team.

Beyond this scenario, the research will be disseminated in other management areas of the graduation, as a way to strengthen and disseminate these practices and their importance in the teaching-learning process.

\section{Discussion}

Although both groups pointed out their fears and anxieties in the context of crisis and instability of their hospitalized relatives, we obtained less dialogue and bonding in the scenario of the pediatric ICU. However, there was a limitation of the study in the sense that we did not distinguish between the needs of the pediatric ICU and the neonatal ICU. In spite of this, the singularity of child de- 
mand was considered and interventions were proposed in this reality.

Family members of geriatric patients, through the ISSL questionnaire, did not present significant scores. This finding contradicts the literature, which states that family members usually present even higher stress scores than those of the patients themselves (Neves et al., 2009). On the other hand, the family members of pediatric patients had high stress scores, covering more than seven items of the stress alert signs(among them, prevail: Knot or pain in the stomach, Muscle strain, Transient diarrhea, Insomnia, difficulty to sleep, Tachycardia, Change of appetite). These data corroborate the receptivity of the relatives in both environments: the relatives of the geriatric patients were more caring about the research, while the family members of pediatric patients were more objective, some refusing to participate in the research, demonstrating anxiety, stress and haste.

In relation to the quantitative analysis, our study is in agreement with the national literature about the predominance of the female sex among the interviewees, especially in the pediatric ICU (prevalence of $73.3 \%$ of women). According to studies, the presence of the mother, can favor the interrelation between child, family and team providing a better adaptation to hospitalization. For this, the health professional should not deny the nucleus in which the patient lives, being the family member very important to the understanding of the patient, and therefore helping in the task of rebalancing the patient and the environment (Diener, Massago, Falavinha, \& Wanderbroocke, 2011).

The understanding and listening to family members' worries by professionals working in the context of hospitalization is of great importance in order to provide a warm and receptive environment. The reception of the family members is a very significant process to help the patient, being able to reduce the emotional changes, facilitating its recovery (Neves et al., 2009).

The context of an ICU is not a common environment for many people. Thus, it is important to prepare and guide the family members before they enter the hospitalization environment (Neves et al., 2009). It can be seen from the statements of family members that there is a lack of information about the dynamics and functioning of an ICU. Thus, it is extremely important for the professionals involved to maintain contact, transmitting informations and demonstrating empathy.

It is imperative that the team has the time to talk and provide every possible support to the family, clearly explaining the patient's evolution, the routines of the sector, the technical and equipment functioning. Thus, the humanization of the hospital environment and of the ICU will also extend care to the family.

The illness of a person and his/her hospitalization in ICU also implies a modification of the family dynamics. The concerns are innumerable and the feeling of helplessness in the face of the situation is very present. The process of separation, and perhaps the prospect of losing a loved one is a phenomenon that spreads throughout the family. Thus, meaningful relationships between the fam- 
ily and the patient should be encouraged through dialogue and demonstration of affection with speech or touch. Literatures suggest that contact with the hospitalized family member helps in the process of the illness and alleviates the suffering of the family member, who ceases to feel powerless in the face of hospitalization (Almeida et al., 2009).

The experience of having a family member hospitalized in an ICU is marked by various feelings, such as fear, insecurity and tension, and can shake the family structure. In this process it is important that health professionals also provide follow-up to families. For this, it is necessary to open more effective channels of communication with the family members.

\section{Conclusion}

In view of the above, we highlight the importance of some strategies, such as: give information about the patient's condition to his/her family, explain the procedures being performed and the purposes of the equipments used; dialogue with the patient's family members about the meanings of the experiences they are having.

In addition to improvements in the quality of the service offered to patients and their families, we see the academic importance for undergraduates in health care courses, by making these practices humanized as part of their teaching, thus contributing to a broader personal and professional formation.

The attention to the family of a patient hospitalized in an ICU should not be forgotten and should be recognized as an important care of the multiprofessional team.

\section{References}

Almeida, A. S., Aragão, N. R. O., Moura, E., Lima, G. C., Hora, E. C., \& Silva, L. A. S. M. (2009). Sentimentos dos familiares em relação ao paciente internado na unidade de terapia intensiva. Revista Brasileira de Enfermagem, 62, 844-849. https://doi.org/10.1590/S0034-71672009000600007

Aymar, C. L. G., Lima, L. S., Santos, C. M. R., Moreno, E. A. C., \& Coutinho, S. B. (2014). Pain Assessment and Management in the NICU: Analysis of an Educational Intervention for Health Professionals. Jornal de Pediatria, 90, 308-315. https://doi.org/10.1016/j.jped.2013.09.008

Baldoino, A. S., \& Veras, R. M. (2016). Analysis of Service-Learning Activities Adopted in Health Courses of Federal University of Bahia. Revista da Escola de Enfermagem da USP, 50, 17-24. https://doi.org/10.1590/S0080-623420160000300003

Bousso, R. S., \& Angelo, M. (2001). Buscando preservar a integridade da unidade familiar: A família vivendo a experiência de ter um filho na UTI. Revista da Escola de Enfermagem da USP, 35, 172-179. https://doi.org/10.1590/S0080-62342001000200012

Brasil (2004). HumanizaSUS: Acolhimento com avaliação e classificação de risco: Um paradigma ético-estético no fazer em saúde. Brasília: Ministério da Saúde, 1-48.

Brasil (2014). Resolução no 3, de 20 de junho de 2014. Institui Diretrizes Curriculares Nacionais do Curso de Graduação em Medicina e dá outras providências. (Vol. 3). Brasília: Diário Oficial da União. 
Diener, A. K., Massago, F. T., Falavinha, P. C., \& Wanderbroocke, A. C. (2011). Visão da equipe sobre a inclusão da família no tratamento em ambiente hospitalar. Anais do II Congresso de Humanização, 1-23.

Engel, G. I. (2000). Pesquisa-ação. Educar em Revista, 16, 181-191. https://doi.org/10.1590/0104-4060.214

Freitas, K. S., Kimura, M., \& Ferreira, K. A. S. L. (2007). Family Members' Needs at Intensive Care Units: Comparative Analysis between a Public and a Private Hospital. Revista Latino-Americana de Enfermagem, 15, 84-92. https://doi.org/10.1590/S0104-11692007000100013

Goldenstein, E. (2006). Um estudo preliminar sobre humanização hospitalar: dando voz à médicos de uma UTI pediatrica sobre suas vivências em um hospital humanizado. Pontifícia Universidade Católica de São Paulo.

Marin, M. J. S., Oliveira, M. A. C., Otani, M. A. P., Cardoso, C. P., Moravcik, M. Y. A. D., Conterno, L. O., \& Siqueira Júnior, A. C. (2014). A integração ensino-serviço na formação de enfermeiros e médicos: A experiência da FAMEMA. Ciência \& Saúde Coletiva, 19, 967-974. https://doi.org/10.1590/1413-81232014193.09862012

Martins, J. J., Nascimento, E. R. P., Geremias, C. K., Schneider, D. G., Schweitzer, G., \& Neto, H. M. (2008). O acolhimento à família na Unidade de Terapia Intensiva: Conhecimento de uma equipe multiprofissional. Revista Eletrônica de Enfermagem, 10, 1091-1101. https://doi.org/10.5216/ree.v10.46816

Minayo, M. C. S. (2012). Análise qualitativa: Teoria, passos e fidedignidade. Ciência \& Saúde Coletiva, 17, 621-626. https://doi.org/10.1590/S1413-81232012000300007

Molina, R. C. M., Varela, P. L. R., Castilho, S. A., Bercini, L. O., \& Marcon, S. S. (2007). Presença da família nas unidades de terapia intensiva pediátrica e neonatal: Visão da equipe multidisciplinar. Escola Anna Nery, 11, 437-444. https://doi.org/10.1590/S1414-81452007000300007

Moraes, P. A., Bertolozzi, M. R., \& Hino, P. (2011). Percepções sobre necessidades de saúde na Atenção Básica segundo usuários de um serviço de saúde. Revista da Escola de Enfermagem da USP, 45, 19-25. https://doi.org/10.1590/S0080-62342011000100003

Neves, F. B. C. S., Dantas, M. P., Bitencourt, A. G. V., Vieira, P. S., Magalhães, L. T., Teles, J. M. M., Messeder, O. H. C. et al. (2009). Análise da satisfação dos familiares em unidade de terapia intensiva. Revista Brasileira de Terapia Intensiva, 21, 32-37. https://doi.org/10.1590/S0103-507X2009000100005

Oliveira, N. E. S., Oliveira, L. M. A. C., Lucchese, R., Alvarenga, G. C., \& Brasil, V. V. (2013). Humanização na teoria e na prática: A construção do agir de uma equipe de enfermeiros. Revista Eletrônica de Enfermagem, 15, 334-343.

https://doi.org/10.5216/ree.v15i2.17916

Poles, K., \& Bousso, R. S. (2006). Compartilhando o processo de morte com a família: A experiência da enfermeira na UTI pediátrica. Revista Latino-Americana de Enfermagem, 14, 207-213. https://doi.org/10.1590/S0104-11692006000200009

Santos, D. G., \& Caregnato, R. C. A. (2013). Familiares de pacientes em coma internados na unidade de terapia intensiva: Percepções e comportamentos. Revista Eletrônica de Enfermagem, 15, 487-495. https://doi.org/10.5216/ree.v15i2.16929

Silveira, R. S., Lunardi, V. L., Lunardi Filho, W. D., \& Oliveira, A. M. N. (2005). Uma tentativa de humanizar a relação da equipe de enfermagem com a família de pacientes internados na UTI. Texto \& Contexto Enfermagem, 14, 125-130. https://doi.org/10.1590/S0104-07072005000500016

Soares, M. (2007). Cuidando da família de pacientes em situação de terminalidade 
internados na unidade de terapia intensiva. Revista Brasileira de Terapia Intensiva, 19, 481-484. https://doi.org/10.1590/S0103-507X2007000400013

Tripp, D. (2005). Pesquisa-ação: Uma introdução metodológica. Educação e Pesquisa, 31, 443-466. https://doi.org/10.1590/S1517-97022005000300009 


\section{Appendix I}

\section{QUESTIONNARIE}

I-Identification data:

1) Age: ( )18- 28 ( ) 29-39 ( ) 40-50 ( ) 51-61 ( ) >61

2) Sex: ( ) Female ( ) Male

3) Education:

4) Religion: ( ) Catholic ( ) Evangelical ( ) Spiritist ( ) Other

5) Do you consider yourself a religious practitioner? ( ) Yes ( ) No

6) What is the degree of relationship with the patient?

7) How often do you visit the patient? $\mathrm{A}($ ) $\mathrm{B}($ ( ) $\mathrm{C}(\mathrm{l}) \mathrm{D}(\mathrm{)} \mathrm{E}(\mathrm{)}$

A. Once a month

B. Once a week

C. Three times a week

D. Four or more times a week

E. Less than once a month

8) Have you had other relatives hospitalized in the ICU? ( ) Yes ( ) No

9) Have you ever had any hospitalization in the ICU? ( ) Yes ( ) No

10) Do you live with the patient? ( ) Yes ( ) No

11) How old is the patient? ( ) zero-1 year ( ) 1 - 2 year ( ) between 2 and 4 years ( ) 5 - 7 years ( ) $<10$ years ( ) 10 years ( ) $60-70$ years ( ) $70-80$ years ( ) $80-90$ years ()$>90$ years

12) How long has the patient been hospitalized? ( ) 1 to 5 days ( ) 1 week ( ) less than a month ( ) two months ( ) more than two months ( ) less than five months ( ) five months or more ( ) less than a year ( ) more than a year

II-Specific questions:

-Closed Questionnaire:

1) Do you feel that you are being treated well by the staff who are taking care of the patient? ( ) Yes ( ) No

2) Are you satisfied with the treatment of the ICU team? ( ) Yes ( ) No

3) Which professional is the one that most talks to you, in the context of this hospitalization?

( ) Nurse ( ) Doctor ( ) Psychologist ( ) All others ( ) Others ( ) Do not know

4) Do you feel powerless in this situation? ( ) Yes ( ) No

5) Do you know why your relative is hospitalized? ( ) Yes ( ) No

6) How is the contact that you have with the family member hospitalized during visits:

( ) Verbal ( ) Non-Verbal ( ) Do Not Maintain Contact.

-Open Questionnaire

A) Do you feel satisfied with the care of the ICU team?

B) How are you feeling right now? 
C) Do you know the state of health of your relative?

D) Are you being regularly informed by the ICU team?

E) Do you make any kind of contact with your hospitalized family member?

F) How is your relationship with the ICU team?

G) What do you think is lacking in regard to the care and information given to the patient's family?

H) Who do you think is the most responsible for the improvement of the hospitalized family member? 


\section{Appendix II}

Lipp Adult Stress Symptoms Inventory (ISSL)

Phase I-Alert (alarm)

It is the phase of contact with the source of stress, with its typical sensations in which the organism loses its balance and prepares itself to face the established situation due to its adaptation. They are unpleasant sensations, providing the conditions for reaction to the stress, fundamental for the survival of the individual.

To identify it, check the symptoms you have experienced in the LAST 24 HOURS:

( ) Cold hands and/or feet

( ) Dry mouth

( ) Knot or pain in the stomach

( ) Increased sweating (too much sweating)

( ) Muscle strain (back, neck, shoulder pain)

( ) Tightening the jaw/grinding of teeth, or biting fingernails or pen tip

( ) Transient Diarrhea

( ) Insomnia, difficulty to sleep

( ) Tachycardia (accelerated heart beats)

( ) Heavy breathing, gasping

( ) Sudden and transient hypertension (sudden and transient high blood pressure)

( ) Change of appetite (eating a lot or having a lack of appetite)

( ) Sudden increase in motivation

( ) Sudden excitement

( ) Sudden willingness to start new projects

ALERT $\rightarrow$ In the occurrence of 7 (SEVEN) or more items in PHASE I

Phase II-Resistance (fight)

Intermediate phase in which the organism seeks the return to balance. It is exhausting, forgetful, tiresome and doubtful. It may occur in this stage the adaptation or elimination of stressors and consequent rebalancing and harmony or progress to the next stage as a result of non-adaptation and/or elimination of the source of stress.

To identify it, point out the symptoms you have experienced in the LAST 


\section{MONTH:}

( ) Problems with memory, forgetfulness

( ) General malaise, with no specific cause

( ) Tingling in the extremities (feet or hands)

( ) Sensation of constant physical exhaustion

( ) Change of appetite

( ) Appearance of dermatological problems (skin)

( ) High blood pressure

( ) Constant Tiredness

( ) Appearance of prolonged gastritis (burning in the stomach, heartburn)

( ) Dizziness, feeling of floating

( ) Excessive emotional sensitivity, thrilled by anything

( ) Doubts about yourself

( ) Constant thinking on a single subject

( ) Excessive irritability

( ) Decreased libido (decreased sexual desire)

RESISTANCE $\rightarrow$ In the occurrence of 4 (four) or more of the items in PHASE II

Phase III-Exhaustion

"Critical and dangerous" phase, occurring a kind of return to the first phase, but aggravated and with physical compromises in the form of diseases.

To identify it, point out the symptoms you have experienced in the LAST 3 (THREE) MONTHS:

( ) Frequent diarrhea

( ) Sexual Difficulties

( ) Tingling in the extremities (hands and feet)

( ) Insomnia

( ) Nervous tics

( ) Confirmed arterial hypertension

( ) Prolonged skin problems (skin)

( ) Extreme change of appetite

( ) Tachycardia (fast heart beat)

( ) Frequent dizziness

( ) Ulcer

( ) Impossibility to Work

( ) Nightmares

( ) Feeling of incompetence in all areas

( ) Desire to run away from everything 
( ) Apathy, lack of willpower, depression or prolonged anger

( ) Excessive tiredness

( ) Constant thinking about the same subject

( ) Irritability without apparent cause

( ) Anguish or daily anxiety

( ) Emotional hypersensitivity

( ) Loss of sense of humor

EXHAUSTION $\rightarrow$ In the occurrence of 9 (nine) or more items in PHASE III 


\section{Appendix III}

INFORMED CONSENT FORM

According to Resolution 196/96 of the National Health Council.

CONSENT OF THE PARTICIPATION OF THE PERSON AS A PARTICIPANT

I, , ID number , signed below, agree to participate in the study "Study with family members of patients in the Intensive Care Unit: an intervention of medical undergraduates" as a participant. I was duly informed and clarified about the research, in which there will be a questionnaire filled out by the participants themselves and an interview, in which the audio of the answers will be recorded for later transcription and analysis. With this, the research seeks to outline the following aspects regarding family members of pediatric and geriatric patients hospitalized at FAMEMA ICUs; differences between the two groups; analysis of family stress and anxiety levels; needs of family members; evaluation of how spirituality and religiosity influence the confrontation of the hospitalization context; analysis, through the family report, of the approaches offered by health professionals who deal with these families; elaboration of an intervention plan to ease the stress and anxiety of family members; evaluation of the effectiveness of the intervention plan drawn up; proportion of the subsidies for the multiprofessional team of the FAMEMA complex for a more humanized care with the families of the hospitalized patients. I was also duly informed of the possible risks and benefits of my participation. I have been assured that I can withdraw my consent at any time, without any implication, and that I may know the results of the study.

I am aware of the above and wish to participate in the research as recommended by the main researcher and researchers who subscribe this document.

Place and date:

Research participant signature

Debora Aiesha Leite Cantelli

(ID: 47.874.543-6)

Karen Mayumi Matsuno

(ID: 39.511.999-6) 
Karin Kojima

(ID: $36.157 .747-3)$

Rubens Yoshinori Kai

(ID: 48.742.530-3)

Submit or recommend next manuscript to SCIRP and we will provide best service for you:

Accepting pre-submission inquiries through Email, Facebook, LinkedIn, Twitter, etc. A wide selection of journals (inclusive of 9 subjects, more than 200 journals)

Providing 24-hour high-quality service

User-friendly online submission system

Fair and swift peer-review system

Efficient typesetting and proofreading procedure

Display of the result of downloads and visits, as well as the number of cited articles Maximum dissemination of your research work

Submit your manuscript at: http://papersubmission.scirp.org/

Or contact ce@scirp.org 